Supporting Information

\title{
Mechanically Robust, Self-healable and Reprocessable Elastomers Enabled by Dynamic Dual Cross-Links
}

\author{
Yi Chen, ${ }^{\dagger}$ Zhenghai Tang, ${ }^{*}{ }^{+}$Yingjun Liu,${ }^{\dagger}$ Siwu $W u,{ }^{\dagger}$ and Baochun Guo ${ }^{*}+$ \\ $\dagger$ Department of Polymer Materials and Engineering, South China University of \\ Technology, Guangzhou 510640, P. R. China
}

This file includes:

Figs. S1 to S22

Tables S1 to S2

References 


\section{Contents}

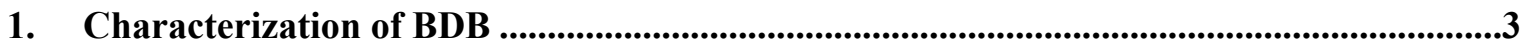

2. Formation and characterization of cross-linked ENR .....................................................4

3. Stress relaxation of BEx samples ..............................................................................................

4. Self-healing properties of BEx samples ........................................................................................9

5. Reprocessability studies of BEx samples........................................................................11

6. Thermogravimetric stability of BEx samples ..............................................................................12

7. Characterization of $\mathrm{Zn}^{2+}-\mathrm{O}$ coordination ....................................................................................13

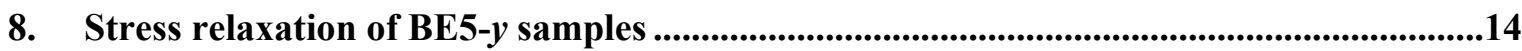

9. Self-healability and reprocessability studies of BE5-y samples............................................15

10. Mechanical properties of BEx samples and comparison with reported self-healing

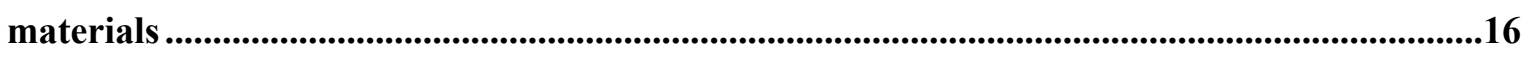

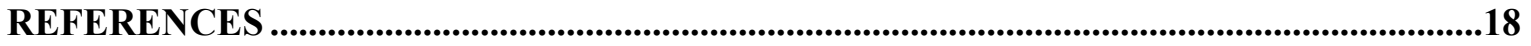




\section{Characterization of BDB}

${ }^{1} \mathrm{H}$ NMR $\left(\mathrm{CDCl}_{3}, 600 \mathrm{MHz}\right)$ : BDB- 8.83 (s, 4H), 4.74 (m, 2H), 4.49 (dd, J=8 Hz, $7 \mathrm{~Hz}$, 2H), 4.18 (dd, J=13 Hz, $5.5 \mathrm{~Hz}, 2 \mathrm{H}), 2.82$ (dd, J=7.5 Hz, $5 \mathrm{~Hz}, 4 \mathrm{H}), 1.49$ ppm (t, J=7.5 Hz, $2 \mathrm{H})$.

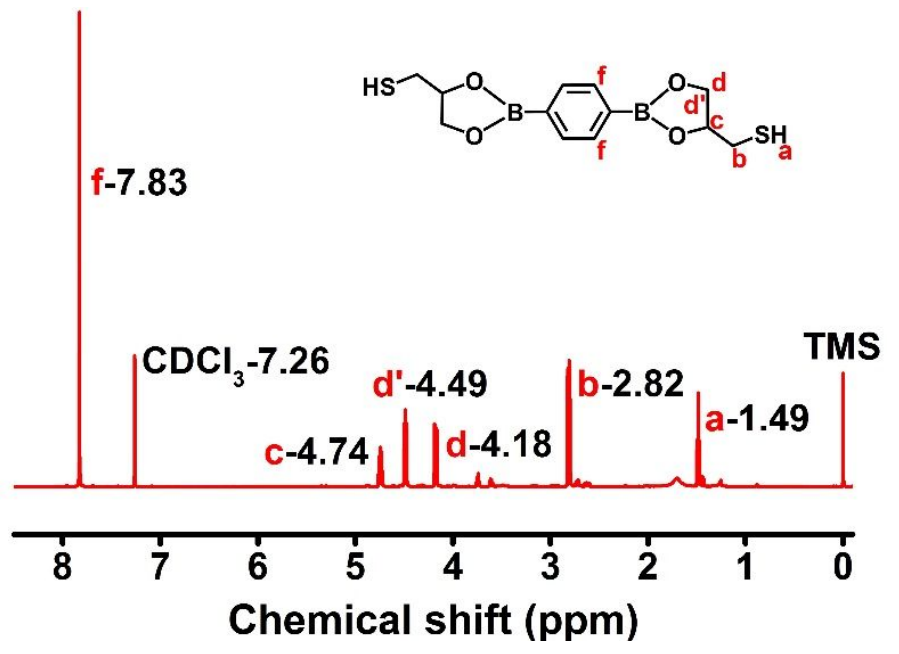

Figure S1. ${ }^{1} \mathrm{H}$ NMR spectrum of BDB.

${ }^{13} \mathrm{C} \mathrm{NMR}\left(\mathrm{CDCl}_{3}, 600 \mathrm{MHz}\right)$ : BDB- $\delta 133.1,76.6,68.8,28.6 \mathrm{ppm}$. Carbon adjacent to boron is not detected.

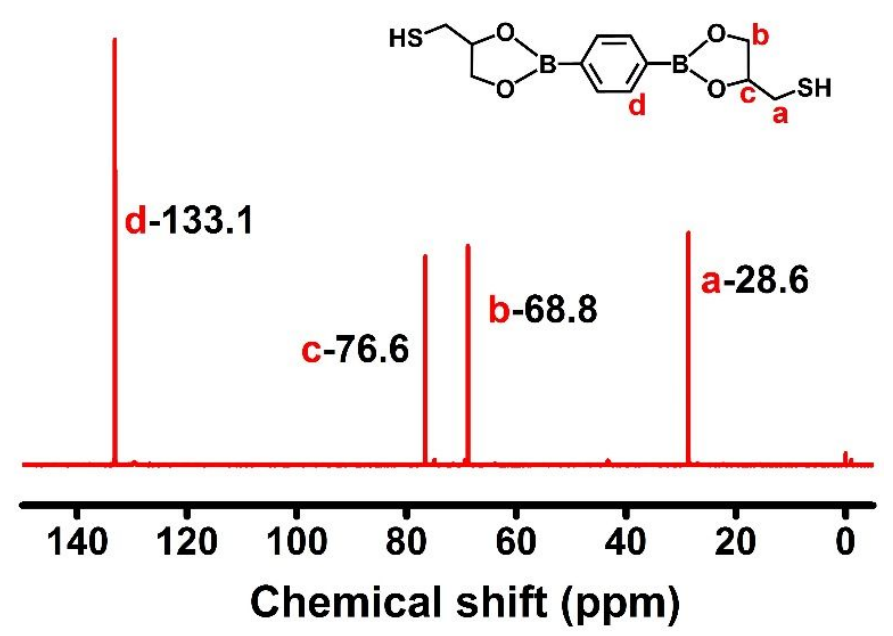

Figure S2. ${ }^{13} \mathrm{C}$ NMR spectrum of BDB. 
${ }^{11} \mathrm{~B} \mathrm{NMR}\left(\mathrm{CDCl}_{3}, 600 \mathrm{MHz}\right)$ : BDB- $\delta 31.5 \mathrm{ppm}$.

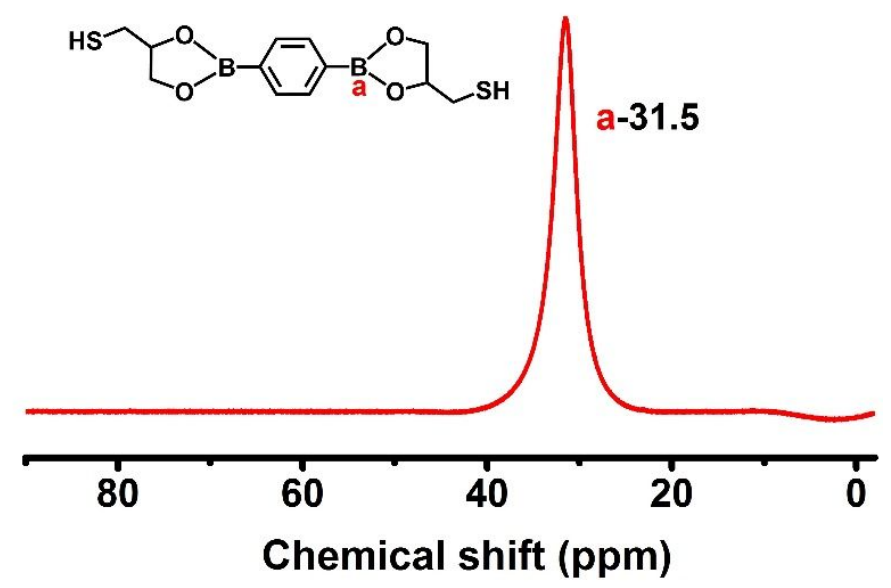

Figure S3. ${ }^{11} \mathrm{~B}$ NMR spectrum of BDB.

\section{Formation and characterization of cross-linked ENR}

In the FTIR spectrum of BDB, the absorptions at 2560 and $1219 \mathrm{~cm}^{-1}$ are due to stretching vibrations of -SH and B-O, respectively. In the case of neat ENR, the absorption at $874 \mathrm{~cm}^{-1}$ is assigned to the stretching vibration of epoxy groups. ${ }^{1}$ Compared with the uncured BE5, the absorption related to -SH completely disappeared after curing.

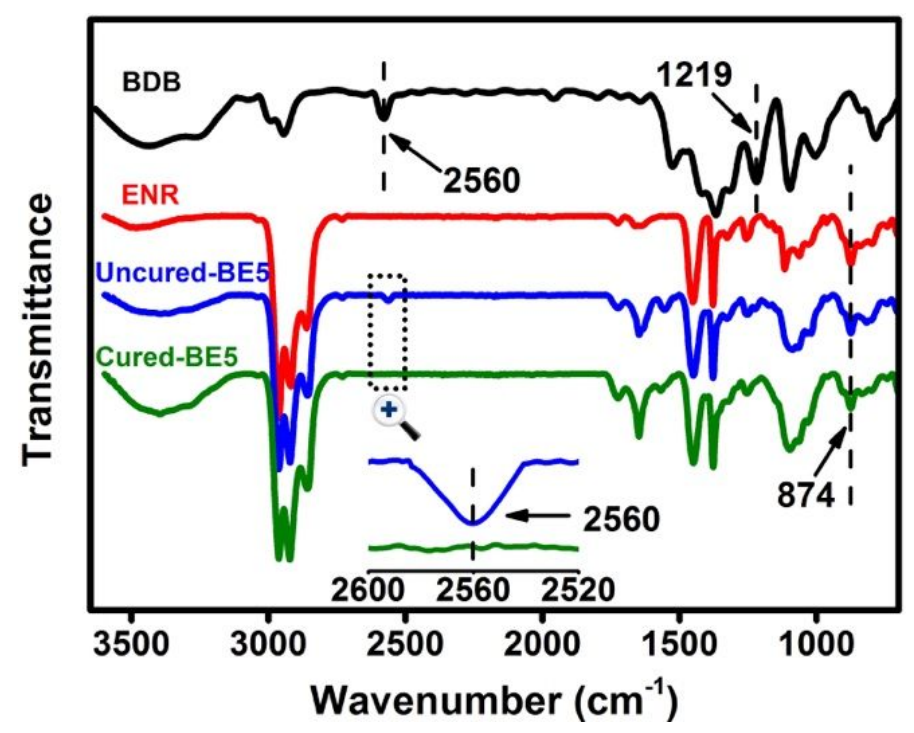

Figure S4. FTIR spectra of BDB, neat ENR, uncured BE5 compound and cured BE5 sample. 


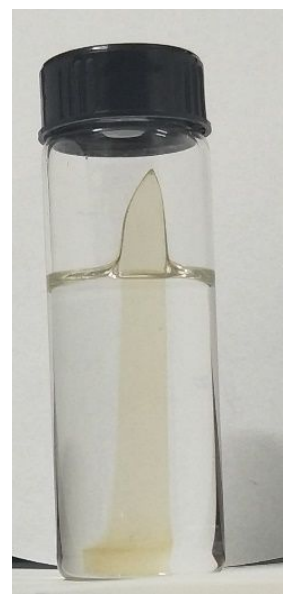

Figure S5. Photo of BE5 swelling in toluene after $72 \mathrm{~h}$.

The cross-linking kinetics can be monitored by measuring the torque value of $\mathrm{BE} x$ compounds at $160{ }^{\circ} \mathrm{C}$ on a rheometer. The torque value firstly increases and then levels off with time. The increased torque is due to the cross-linking of ENR. It can be seen that the covalent cross-linking reaction is accomplished within $40 \mathrm{~min}$. In addition, the maximum torque value consistently increases with BDB loading, which indicates an increase in the cross-linking density.

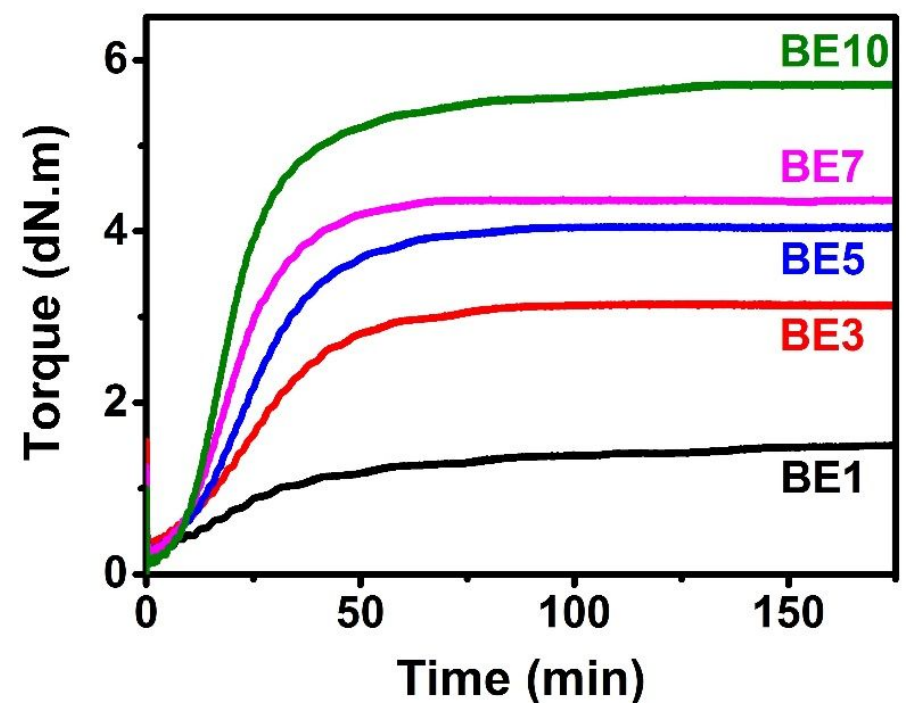

Figure S6. Evolution of torque for BEx at $160^{\circ} \mathrm{C}$.

\section{Equilibrium swelling experiments.}

Sol fraction, swelling ratio and cross-linking density was determined by equilibrium swelling experiment in toluene based on Flory-Rehner equation. ${ }^{2-3}$ Equilibrium swelling 
experiments were conducted by immersing vulcanizations in toluene at room temperature for $72 \mathrm{~h}$, and the solvent is replaced with fresh solvent for each $24 \mathrm{~h}$. After swelling, the solvent was wiped off quickly from the sample surface using filter paper, and the samples were immediately weighed and then dried in a vacuum oven at $60{ }^{\circ} \mathrm{C}$ until constant weight. Three specimens were measured for each sample.

The swelling ratio is defined as $\left(\mathrm{m}_{1}-\mathrm{m}_{2}\right) / \mathrm{m}_{2}$, and sol fraction is determined as $\left(\mathrm{m}_{0}-\mathrm{m}_{2}\right) / \mathrm{m}_{0}$. The volume fraction of SBR in the swollen gel, $V_{r}$, was calculated by the following

\section{Equation S1:}

$$
V_{r}=\frac{\left(m_{2}-m_{0} \varphi\right) / \rho_{r}}{\left(m_{2}-m_{0} \varphi\right) / \rho_{r}+\left(m_{1}-m_{2}\right) / \rho_{s}}
$$

where $\mathrm{m}_{0}$ is the sample mass before swelling, $\mathrm{m}_{1}$ and $\mathrm{m}_{2}$ are the weights of the swollen and deswollen sample, respectively; $\varphi$ is the weight fraction of the insoluble components, $\rho_{r}$ and $\rho_{s}$ are the densities of the rubber and solvent, respectively.

The elastically active network chain density can be calculated by the well-known FloryRehner Equation S2:

$$
V_{e}=-\frac{\ln \left(1-V_{r}\right)+V_{r}+\chi V_{r}^{2}}{V_{s}\left(V_{r}^{1 / 3}-V_{r} / 2\right)}
$$

where $\chi$ is the Flory-Huggins polymer solvent interaction parameter ( 0.341 for ENR and toluene), and $V_{S}$ is the molar volume of the solvent $\left(106.5 \mathrm{~cm}^{3} \cdot \mathrm{mol}^{-1}\right.$ for toluene).

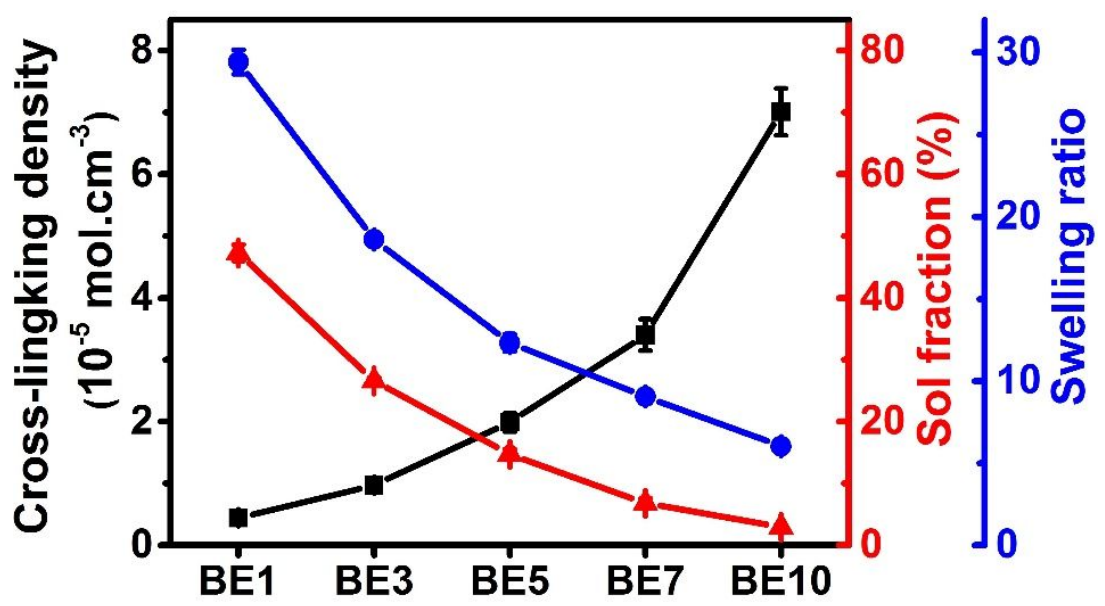

Figure S7. Cross-linking density, sol fraction and swelling ratio for BEx series. 
3. Stress relaxation of BEx samples

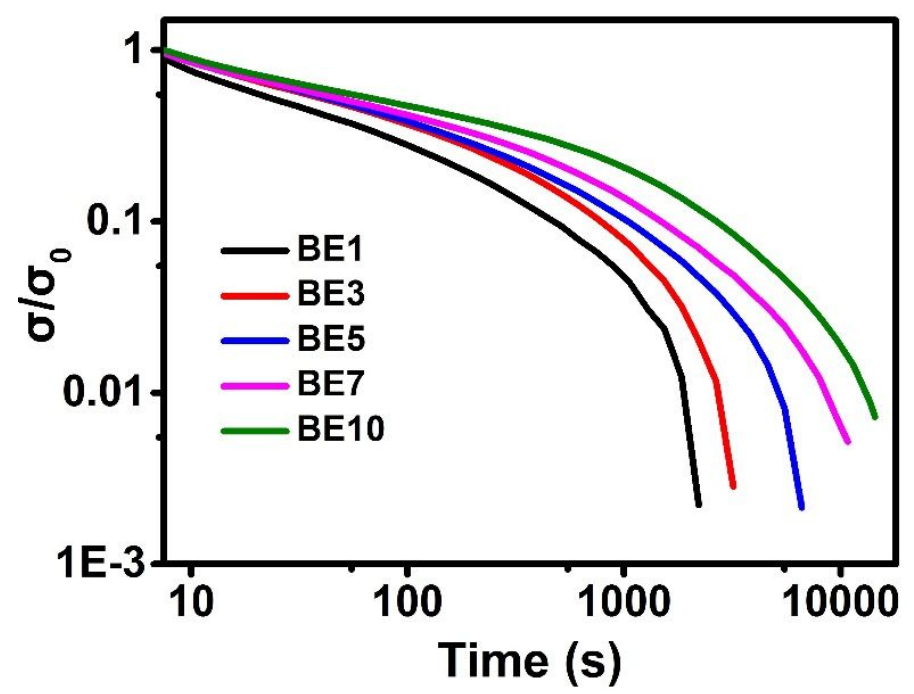

Figure S8. Stress relaxation curves for BEx series at $160^{\circ} \mathrm{C}$.

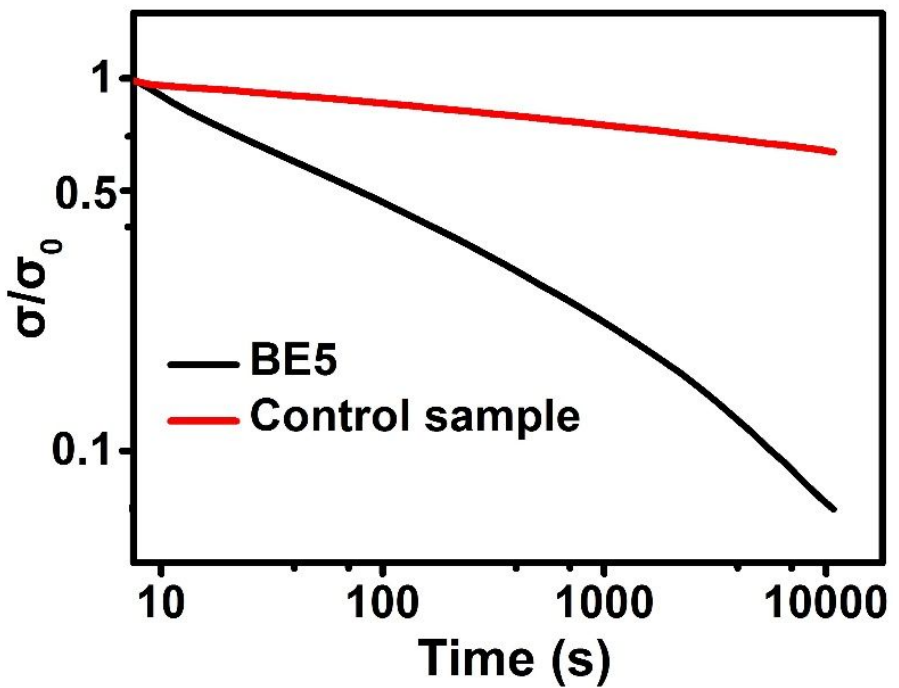

Figure S9. Stress relaxation curves of BE5 and control sample at $140{ }^{\circ} \mathrm{C}$. 


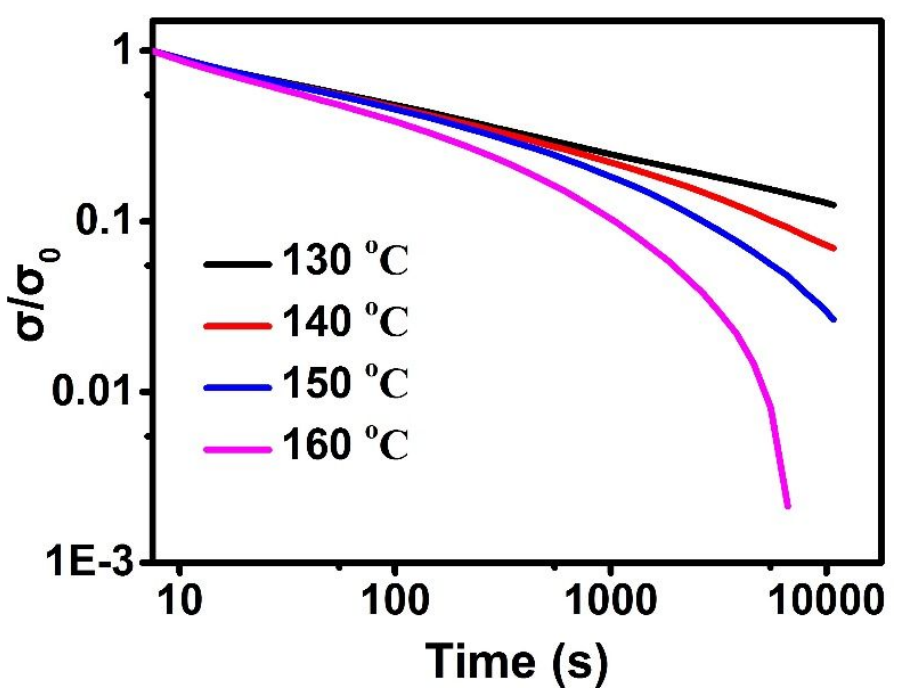

Figure S10. Stress relaxation curves for BE5 at different temperatures ranging from 130 to $160{ }^{\circ} \mathrm{C}$.

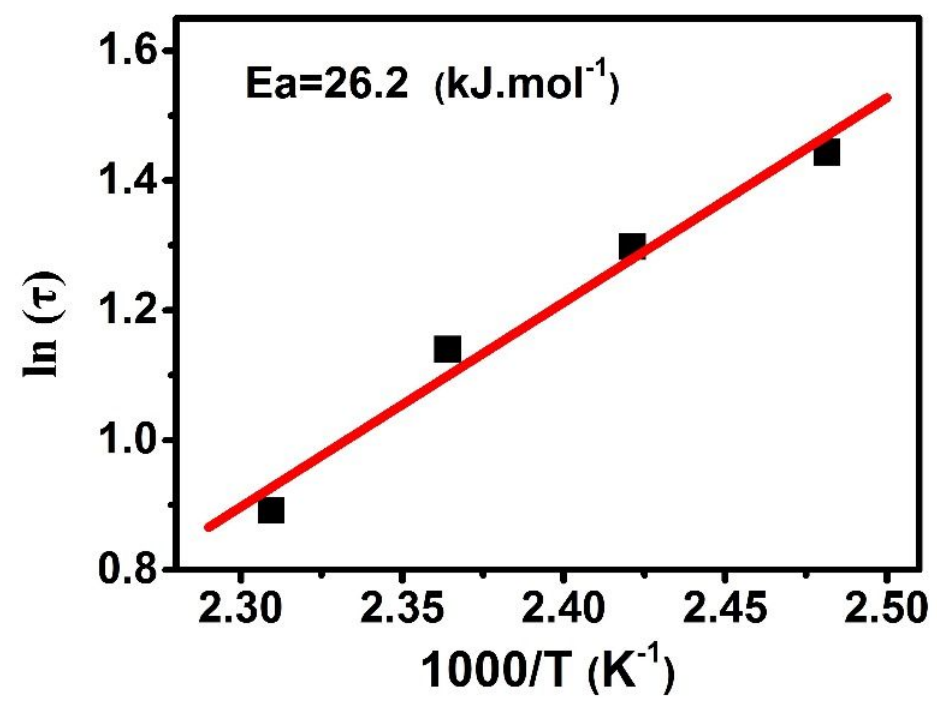

Figure S11. Fitting of characteristic relaxation time to temperature using the Arrhenius equation. 


\section{Self-healing properties of BEx samples}

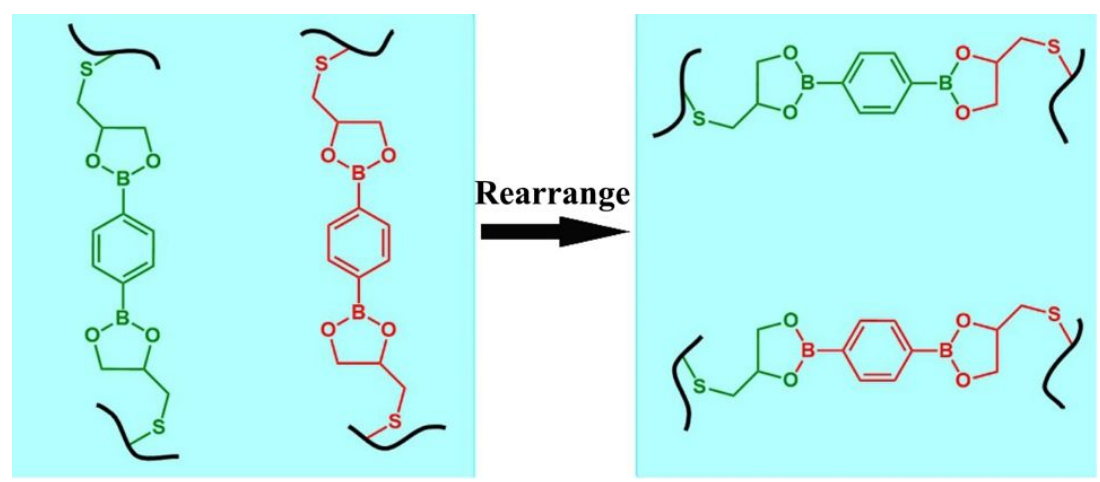

Figure S12. Network rearrangement of BEx samples via exchange reaction of boronic ester. 

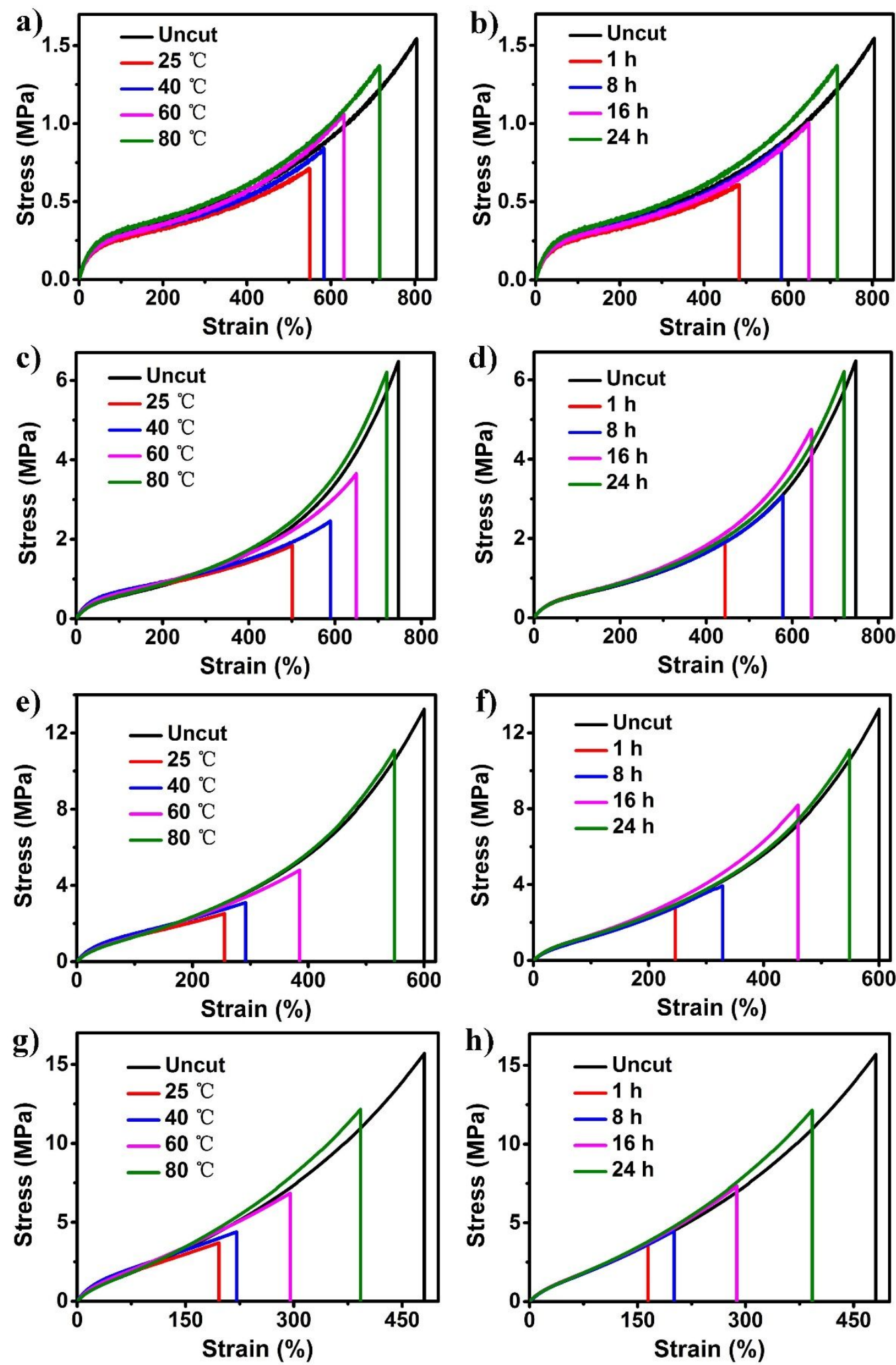

Figure S13. Typical stress-strain curves of (a)-(b) BE1, (c)-(d) BE3, (e)-(f) BE7, (g)-(h) BE10 after healing at various temperatures for $24 \mathrm{~h}$ and healing at $80^{\circ} \mathrm{C}$ for various times. 


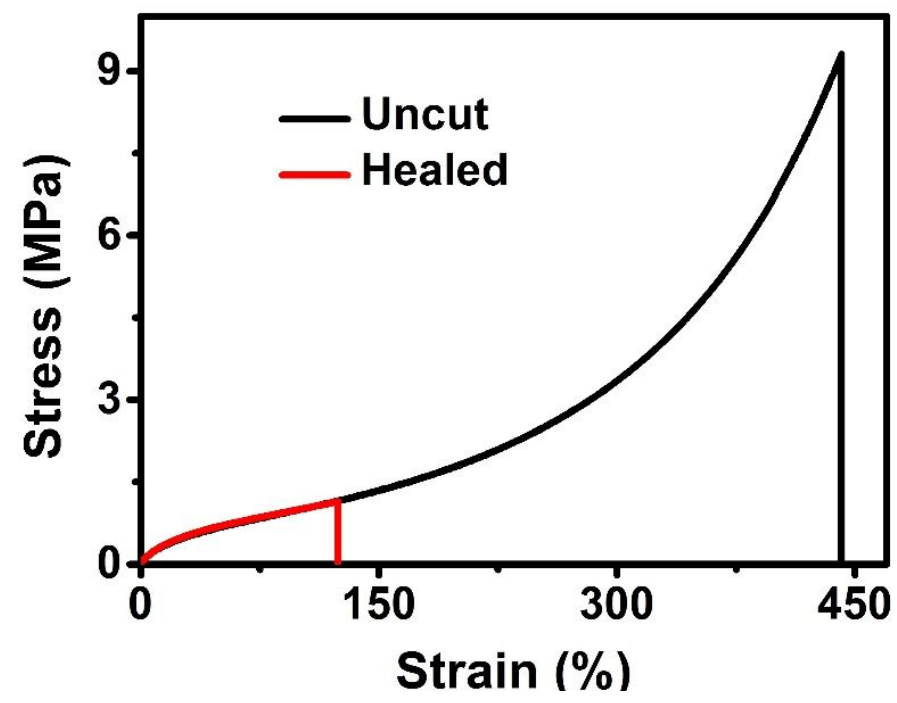

Figure S14. Stress-strain curves of reference sample before and after healing at $80^{\circ} \mathrm{C}$ for $24 \mathrm{~h}$.

5. Reprocessability studies of BEx samples
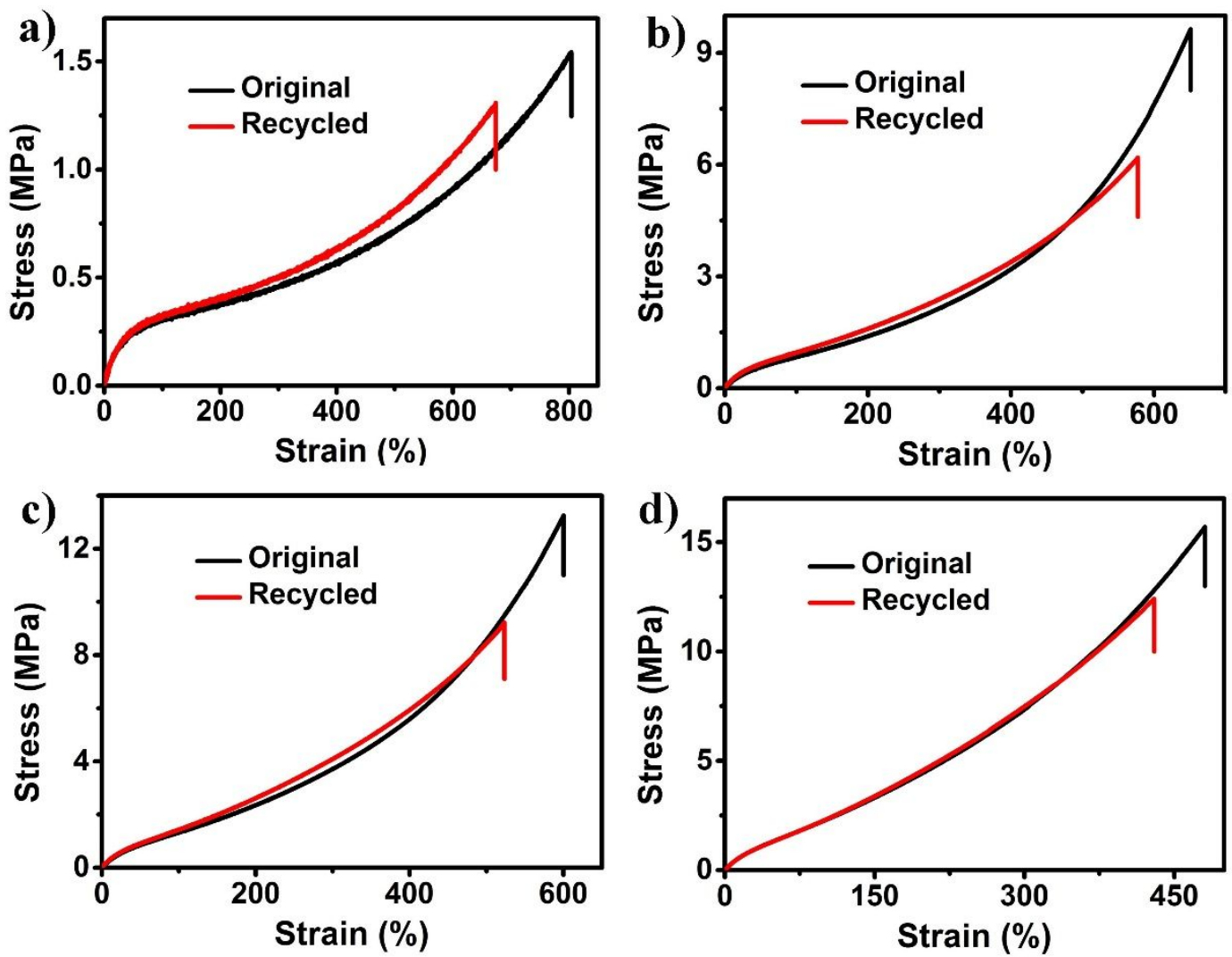

Figure S15. Stress-strain curves of original and recycled for (a) BE1, (b) BE5, (c) BE7 and (d) BE10. 


\section{Thermogravimetric stability of BEx samples}

TGA experiments show that the samples have an onset degradation temperature around $280{ }^{\circ} \mathrm{C}$ and negligible weight loss after keeping them at $160{ }^{\circ} \mathrm{C}$ for $2 \mathrm{~h}$.

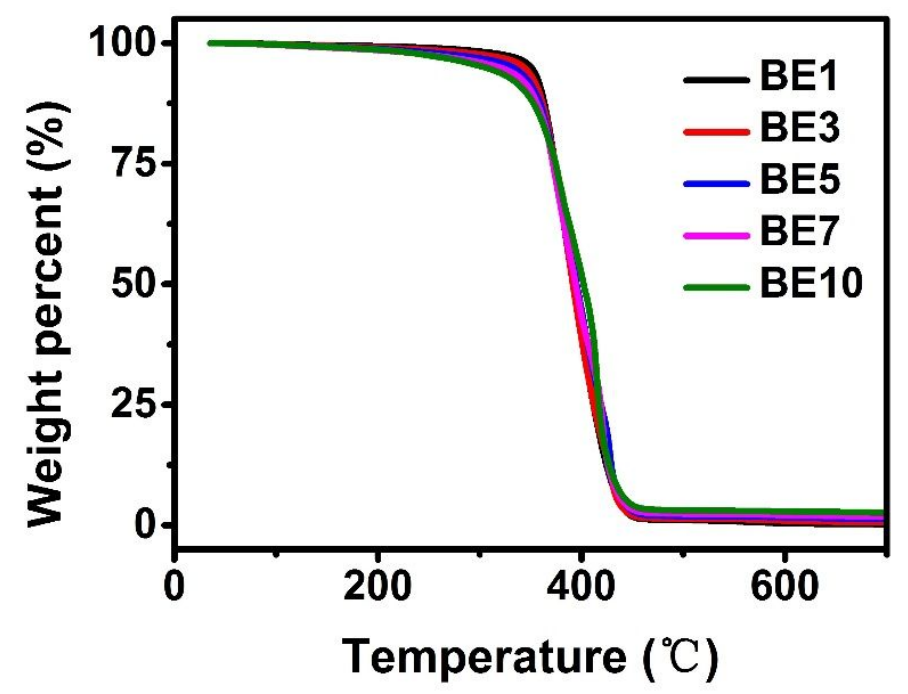

Figure S16. TGA curves of BEx samples.

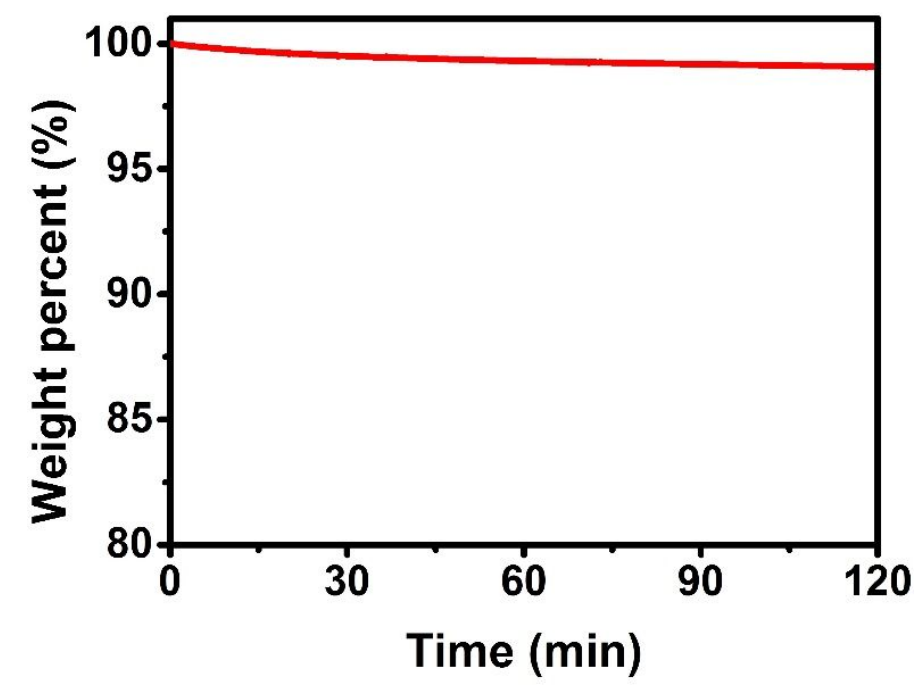

Figure S17. Isothermal TGA curve of BE3 under nitrogen atmosphere at $160^{\circ} \mathrm{C}$. 


\section{Characterization of $\mathrm{Zn}^{2+}-\mathrm{O}$ coordination}

To envisage the coordination between $\mathrm{Zn}^{2+}$ and epoxy groups and eliminate the confounding influence of $\mathrm{BDB}, \mathrm{ENR}-\mathrm{ZnCl}_{2}$ model compound was prepared by mixing ENR and $\mathrm{ZnCl}_{2}$ (molar ratio of epoxy group to zinc ion is $3: 1$ ) in tetrahydrofuran and then drying to produce a film for FTIR and Raman measurements. In the FTIR spectrum of ENR-ZnCl 2 model compound, the absorptions at 874 and $1256 \mathrm{~cm}^{-1}$ that are associated with the asymmetric and symmetric vibrations of epoxy ring are drastically decreased, and a newly emerging absorption at $905 \mathrm{~cm}^{-1}$ is observed, which can be ascribed to the coordination between $\mathrm{Zn}^{2+}$ and oxygen in epoxy groups. ${ }^{4}$

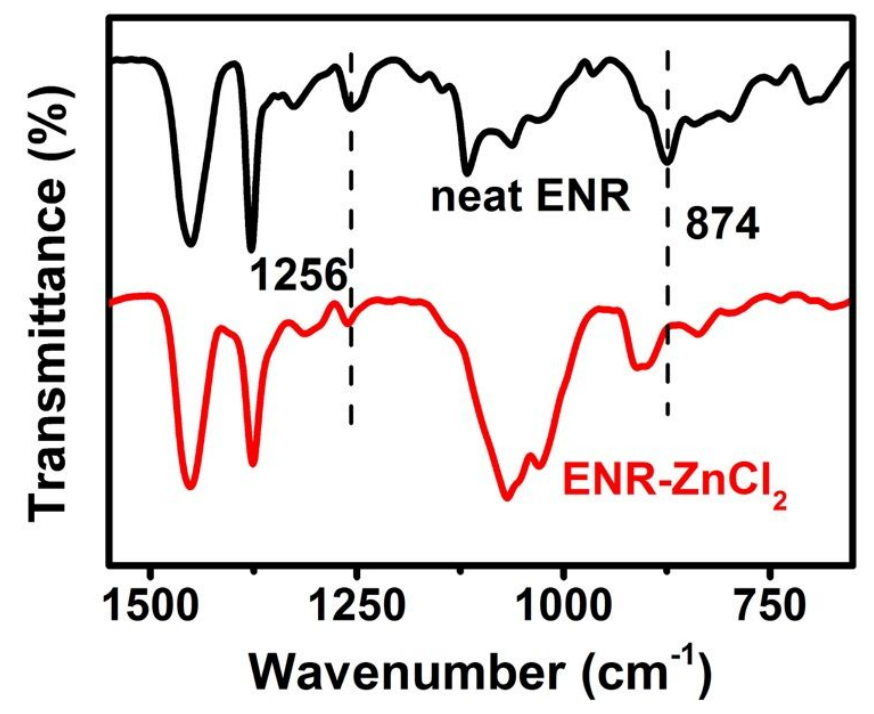

Figure S18. FTIR spectra of neat ENR and ENR- $\mathrm{ZnCl}_{2}$ model compound. The spectra are normalized by using the absorption intensity of $-\mathrm{CH}_{2}$ - at $1451 \mathrm{~cm}^{-1}$ as an internal reference. 
When compared to neat ENR, a new band around $300 \mathrm{~cm}^{-1}$ is observed in the Raman spectrum of ENR- $\mathrm{ZnCl}_{2}$ model compound although the baseline is lifted due to the existence of fluorescence and noises, providing convincing evidence for the formation of $\mathrm{Zn}^{2+}-\mathrm{O}$ coordination. $^{5}$

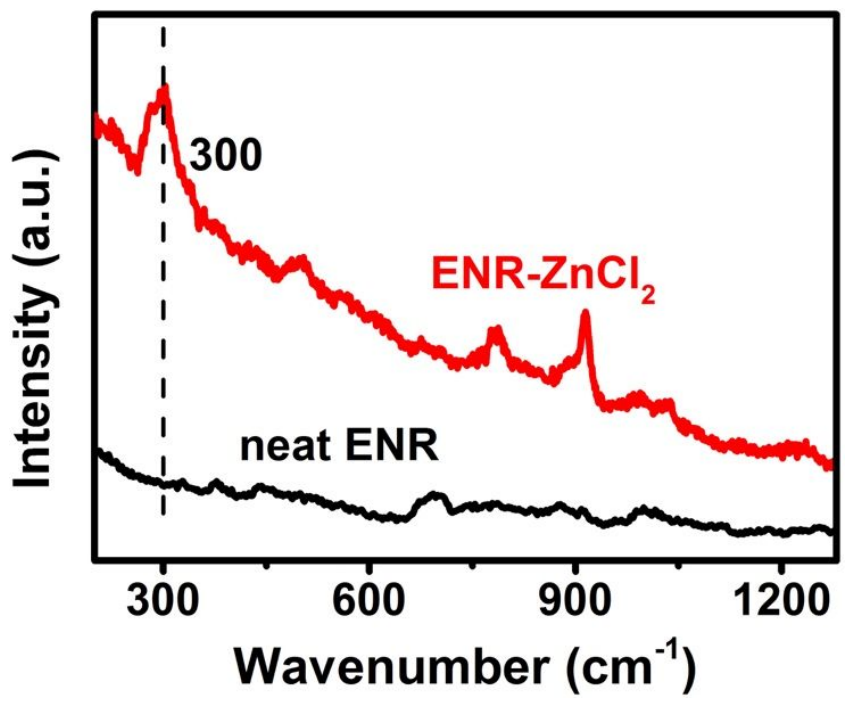

Figure S19. Raman spectra of neat ENR and $\mathrm{ENR}-\mathrm{ZnCl}_{2}$ mixture.

\section{Stress relaxation of BE5-y samples}

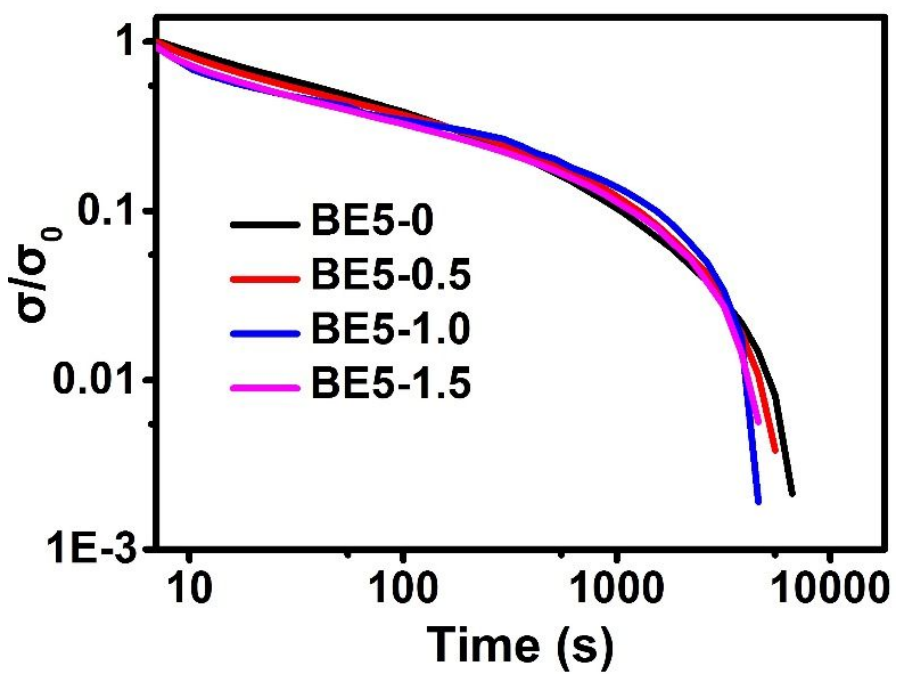

Figure S20. Stress relaxation curves for BE5-y series at $160{ }^{\circ} \mathrm{C}$. 
9. Self-healability and reprocessability studies of BE5-y samples

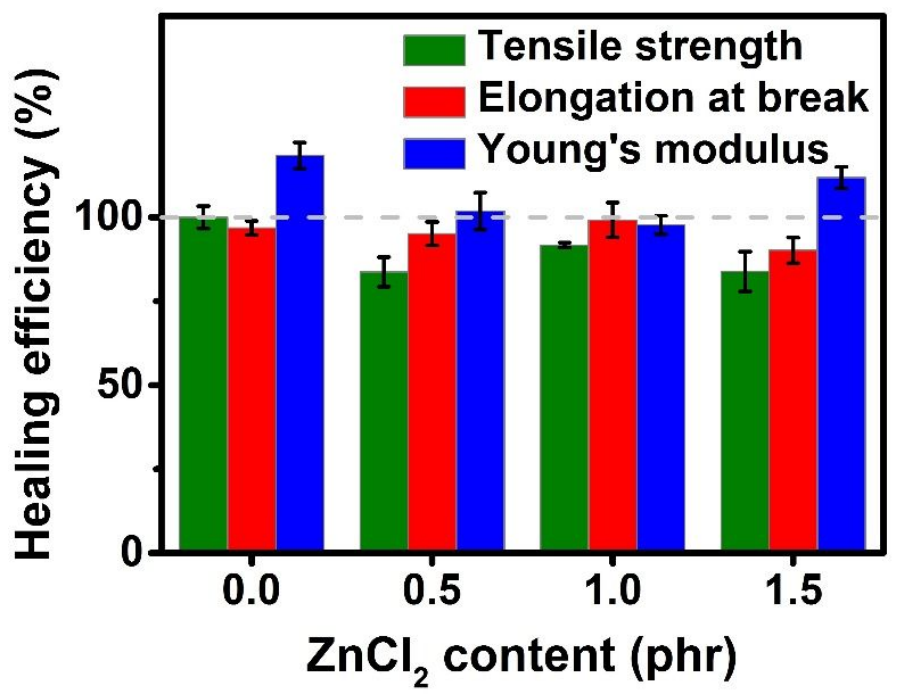

Figure S21. Healing efficiency of BE5-y with different $\mathrm{ZnCl}_{2}$ contents after being healed at $80{ }^{\circ} \mathrm{C}$ for $24 \mathrm{~h}$.

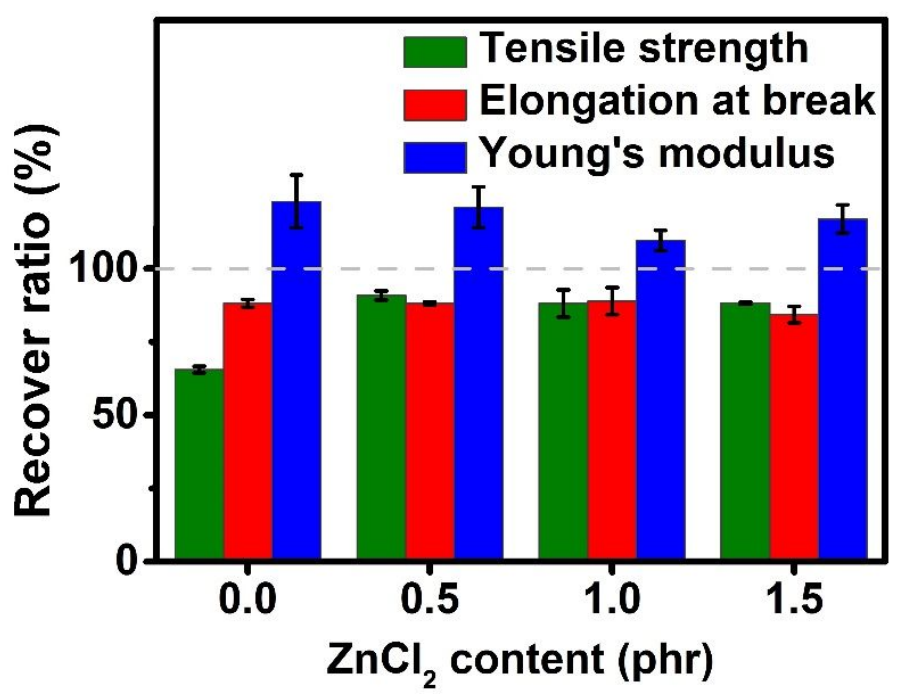

Figure S22. Recover ratio of BE5-y series after being recycled. 


\section{Mechanical properties of BEx samples and comparison with reported self-healing materials}

Table S1. Mechanical properties of BEx samples.

\begin{tabular}{ccccc}
\hline Sample & $\begin{array}{c}\text { Tensile strength } \\
(\mathrm{MPa})\end{array}$ & $\begin{array}{c}\text { Elongation at } \\
\text { break }(\%)\end{array}$ & $\begin{array}{c}\text { Young's modulus } \\
(\mathrm{MPa})\end{array}$ & $\begin{array}{c}\text { Stress at 100\% } \\
\text { Strain (MPa) }\end{array}$ \\
\hline BE1 & $1.60 \pm 0.06$ & $811 \pm 9$ & $0.85 \pm 0.09$ & $0.30 \pm 0.01$ \\
\hline BE3 & $6.31 \pm 0.25$ & $727 \pm 28$ & $1.18 \pm 0.13$ & $0.56 \pm 0.01$ \\
BE5 & $9.55 \pm 0.13$ & $648 \pm 5$ & $1.58 \pm 0.14$ & $0.83 \pm 0.01$ \\
\hline BE7 & $12.53 \pm 0.72$ & $595 \pm 7$ & $2.64 \pm 0.14$ & $1.22 \pm 0.02$ \\
\hline BE10 & $14.63 \pm 0.56$ & $475 \pm 8$ & $4.45 \pm 0.12$ & $2.17 \pm 0.01$ \\
\hline
\end{tabular}

Table S2. Comparison on the mechanical performance between reported self-healing systems and BEx samples.

\begin{tabular}{|c|c|c|c|c|c|c|}
\hline Polymer & Type of dynamic bond & $\begin{array}{l}\text { Strength } \\
(\mathrm{MPa})\end{array}$ & $\begin{array}{l}\text { Breaking } \\
\text { strain }(\%)\end{array}$ & Healing condition & $\begin{array}{l}\text { Healing } \\
\text { efficiency }\end{array}$ & Ref \\
\hline \multirow{6}{*}{ PDMS } & $\begin{array}{l}\text { Disulfide and hydrogen } \\
\text { bonds }\end{array}$ & 0.87 & 2745 & $65^{\circ} \mathrm{C}$ for $2 \mathrm{~h}$ & $97 \%$ & 6 \\
\hline & $\pi-\pi$ interaction & 0.3 & 1400 & $80^{\circ} \mathrm{C}$ for $1 \mathrm{~h}$ & $\sim 100 \%$ & 7 \\
\hline & Diels-Alder reaction & 0.61 & 51 & $\begin{array}{c}140^{\circ} \mathrm{C} \text { for } 3 \mathrm{~h} \text { and } \\
80^{\circ} \mathrm{C} \text { for } 24 \mathrm{~h}\end{array}$ & $95 \%$ & 8 \\
\hline & \multirow{3}{*}{ Metal-ligand bonds } & 0.35 & 330 & $60^{\circ} \mathrm{C}$ for $24 \mathrm{~h}$ & $88 \%$ & 9 \\
\hline & & 0.36 & 2550 & $80^{\circ} \mathrm{C}$ for $20 \mathrm{~h}$ & $95 \%$ & 10 \\
\hline & & 1.12 & 560 & $120^{\circ} \mathrm{C}$ for $24 \mathrm{~h}$ & $70 \%$ & 11 \\
\hline OLE & Hydrogen bond & 4.3 & 190 & $\begin{array}{l}\text { hot-pressing at } \\
160^{\circ} \mathrm{C} \text { for } 10 \mathrm{~min}\end{array}$ & $83 \%$ & 12 \\
\hline
\end{tabular}




\begin{tabular}{|c|c|c|c|c|c|c|}
\hline & Boronic ester bonds & 2.68 & 215 & $80{ }^{\circ} \mathrm{C}$ for $24 \mathrm{~h}$ & $>80 \%$ & 13 \\
\hline & Diels-Alder reaction & 3.6 & 468 & $100^{\circ} \mathrm{C}$ for $5 \mathrm{~h}$ & $90 \%$ & 14 \\
\hline & Disulfide bonds & 3.2 & 380 & $110^{\circ} \mathrm{C}$ for $12 \mathrm{~h}$ & $72 \%$ & 15 \\
\hline \multirow{6}{*}{$\mathrm{PU}$} & \multirow{2}{*}{ Disulfide bonds } & 11 & 720 & $80^{\circ} \mathrm{C}$ for $4 \mathrm{~h}$ & $92 \%$ & 16 \\
\hline & & 2.62 & 787 & $75^{\circ} \mathrm{C}$ for $48 \mathrm{~h}$ & $95 \%$ & 17 \\
\hline & \multirow{2}{*}{ Diels-Alder reaction } & 5.4 & 98 & $\begin{array}{l}130^{\circ} \mathrm{C} \text { for } 5 \mathrm{~min} \\
\text { and } 50{ }^{\circ} \mathrm{C} \text { for } 48 \mathrm{~h}\end{array}$ & $92 \%$ & 18 \\
\hline & & 6.55 & 444 & $120^{\circ} \mathrm{C}$ for $15 \mathrm{~min}$ & $71 \%$ & 19 \\
\hline & Metal-ligand bonds & 9.1 & 1110 & $60^{\circ} \mathrm{C}$ for $24 \mathrm{~h}$ & $\sim 100 \%$ & 20 \\
\hline & Alkoxyamine bonds & 5.5 & 180 & $80^{\circ} \mathrm{C}$ for $2.5 \mathrm{~h}$ & $70 \%$ & 21 \\
\hline PPG & $\begin{array}{l}\text { Disulfide and metal- } \\
\text { ligand bonds }\end{array}$ & 0.15 & 150 & $80{ }^{\circ} \mathrm{C}$ for $5 \mathrm{~h}$ & $76 \%$ & 22 \\
\hline \multirow{3}{*}{ NR } & Disulfide bonds & 0.55 & 517 & $70{ }^{\circ} \mathrm{C}$ for $7 \mathrm{~h}$ & $80 \%$ & 23 \\
\hline & Ionic interaction & 1.53 & 436 & $80^{\circ} \mathrm{C}$ for $3 \mathrm{~min}$ & $51 \%$ & 24 \\
\hline & Ionic interaction & 0.63 & 340 & $80^{\circ} \mathrm{C}$ for $1 \mathrm{~min}$ & $73 \%$ & 25 \\
\hline \multirow{2}{*}{ PSU } & \multirow{2}{*}{ Disulfide bonds } & 1.02 & 157 & $75^{\circ} \mathrm{C}$ for $6 \mathrm{~h}$ & $90 \%$ & 26 \\
\hline & & 0.5 & 65 & $60{ }^{\circ} \mathrm{C}$ for $1 \mathrm{~h}$ & $97 \%$ & 27 \\
\hline \multirow{2}{*}{$\mathrm{PA}$} & Thiol-Michael reaction & 0.25 & 520 & $90^{\circ} \mathrm{C}$ for $16 \mathrm{~h}$ & $\sim 90 \%$ & 28 \\
\hline & Ionic bonds & 1.4 & 325 & $80^{\circ} \mathrm{C}$ for $30 \mathrm{~min}$ & $\sim 100 \%$ & 29 \\
\hline \multirow{2}{*}{ ENR } & $\beta$-hydroxyl esters & 5.76 & 764 & $160^{\circ} \mathrm{C}$ for $3 \mathrm{~h}$ & $83 \%$ & 30 \\
\hline & Boronic ester bonds & 14.63 & 475 & $80^{\circ} \mathrm{C}$ for $24 \mathrm{~h}$ & $>90 \%$ & $\begin{array}{l}\text { This } \\
\text { work }\end{array}$ \\
\hline
\end{tabular}

PDMS (polydimethylsiloxane), OLE (olefin elastomer), PU (polyurethane), PPG (poly(propylene glycol)), NR (natural rubber), PSU (polysulfide), PA (polyacrylate), 
ENR(epoxidized natural rubber).

\section{REFERENCES}

(1) Lin, T.; Zhang, X.; Tang, Z.; Guo, B. Renewable conjugated acids as curatives for high-performance rubber/silica composites. Green Chem. 2015, 17, 3301-3305.

(2) Flory, P. J.; Rehner, J. Statistical Mechanics of Cross-Linked Polymer Networks I. Rubber like Elasticity. J. Chem. Phys. 1943, 11, 512-520.

(3) Flory, P. J. Statistical Mechanics of Swelling of Network Structures. J. Chem. Phys. 1950, 18, 108111.

(4) Liu, X.; Su, G.; Guo, Q.; Lu, C.; Zhou, T.; Zhou, C.; Zhang, X. Hierarchically Structured Self-Healing Sensors with Tunable Positive/Negative Piezoresistivity. Adv. Funct. Mater. 2018, 28, 1706658.

(5) Zhang, X.; Tang, Z.; Guo, B.; Zhang, L. Enabling Design of Advanced Elastomer with Bioinspired Metal-Oxygen Coordination. ACS Appl. Mater. Interfaces 2016, 8, 32520-32527.

(6) Xu, W.; Huang, L. B.; Hao, J. Fully Self-healing and Shape-tailorable Triboelectric Nanogenerators Based on Healable Polymer and Magnetic-assisted Electrode. Nano Energy 2017, 40, 399-407.

(7) Mei, J. F.; Jia, X. Y.; Lai, J. C.; Sun, Y.; Li, C. H.; Wu, J. H.; Cao, Y.; You, X. Z.; Bao, Z. A Highly Stretchable and Autonomous Self-Healing Polymer Based on Combination of Pt- Pt and $\pi-\pi$ Interactions. Macromol. Rapid Commun. 2016, 37, 1667-1675.

(8) Zhao, J.; Xu, R.; Luo, G.; Wu, J.; Xia, H. A self-healing, re-moldable and biocompatible crosslinked polysiloxane elastomer. J. Mater. Chem. B. 2016, 4, 982-989.

(9) Liu, L.; Liang, S.; Huang, Y.; Hu, C.; Yang, J. A stretchable polysiloxane elastomer with self-healing capacity at room temperature and solvatochromic properties. Chem. Commun. 2017, 53, 12088-12091.

(10) Jia, X. Y.; Mei, J. F.; Lai, J. C.; Li, C. H.; You, X. Z. A Highly Stretchable Polymer that Can Be Thermally Healed at Mild Temperature. Macromol. Rapid Commun. 2016, 37, 952-956.

(11) Jia, X. Y.; Mei, J. F.; Lai, J. C.; Li, C. H.; You, X. Z. A self-healing PDMS polymer with solvatochromic properties. Chem. Commun. 2015, 51, 8928-8930.

(12) Liu, X.; Lu, C.; Wu, X.; Zhang, X. Self-healing strain sensors based on nanostructured supramolecular conductive elastomers. J. Mater. Chem. A 2017, 5, 9824-9832.

(13) Chen, Y.; Tang, Z.; Zhang, X.; Liu, Y.; Wu, S.; Guo, B. Covalently Cross-Linked Elastomers with 
Self-Healing and Malleable Abilities Enabled by Boronic Ester Bonds. ACS Appl. Mater. Interfaces 2018, $10,24224-24231$.

(14) Kuang, X.; Liu, G.; Dong, X.; Wang, D. Enhancement of Mechanical and Self-Healing Performance in Multiwall Carbon Nanotube/Rubber Composites via Diels-Alder Bonding. Macromol. Mater. Eng. 2016, 301, 535-541.

(15) Xiang, H. P.; Qian, H. J.; Lu, Z. Y.; Rong, M. Z.; Zhang, M. Q. Crack healing and reclaiming of vulcanized rubber by triggering the rearrangement of inherent sulfur crosslinked networks. Green Chem. 2015, 17, 4315-4325.

(16) Xu, Y.; Chen, D. A Novel Self-Healing Polyurethane Based on Disulfide Bonds. Macromol. Chem. Phys. 2016, 217, 1191-1196.

(17) Gao, W.; Bie, M.; Quan, Y.; Zhu, J.; Zhang, W. Self-healing, reprocessing and sealing abilities of polysulfide-based polyurethane. Polymer 2018, 151, 27-33.

(18) Fu, G.; Yuan, L.; Liang, G.; Gu, A. Heat-resistant polyurethane films with great electrostatic dissipation capacity and very high thermally reversible self-healing efficiency based on multi-furan and liquid multi-maleimide polymers. J. Mater. Chem. A. 2016, 4, 4232-4241.

(19) Feng, L.; Yu, Z.; Bian, Y.; Lu, J.; Shi, X.; Chai, C. Self-healing behavior of polyurethanes based on dual actions of thermo-reversible Diels-Alder reaction and thermal movement of molecular chains. Polymer 2017, 124, 48-59.

(20) Wang, Z.; Xie, C.; Yu, C.; Fei, G.; Wang, Z.; Xia, H. A Facile Strategy for Self-Healing Polyurethanes Containing Multiple Metal-Ligand Bonds. Macromol. Rapid Commun. 2018, 39, 1700678. (21) Yuan, C. e.; Rong, M. Z.; Zhang, M. Q. Self-healing polyurethane elastomer with thermally reversible alkoxyamines as crosslinkages. Polymer 2014, 55, 1782-1791.

(22) Liu, J.; Liu, Y.; Wang, Y.; Zhu, J.; Yu, J.; Hu, Z. Disulfide bonds and metal-ligand co-crosslinked network with improved mechanical and self-healing properties. Mater. Today Commun. 2017, 13, 282289.

(23) Hernández, M.; Grande, A. M.; Dierkes, W.; Bijleveld, J.; van der Zwaag, S.; García, S. J. Turning Vulcanized Natural Rubber into a Self-Healing Polymer: Effect of the Disulfide/Polysulfide Ratio. ACS Sus. Chem. Eng. 2016, 4, 5776-5784.

(24) Xu, C.; Cao, L.; Huang, X.; Chen, Y.; Lin, B.; Fu, L. Self-Healing Natural Rubber with Tailorable 
Mechanical Properties Based on Ionic Supramolecular Hybrid Network. ACS Appl. Mater. Interfaces 2017, 9, 29363-29373.

(25) Xu, C.; Cao, L.; Lin, B.; Liang, X.; Chen, Y. Design of Self-Healing Supramolecular Rubbers by Introducing Ionic Cross-Links into Natural Rubber via a Controlled Vulcanization. ACS Appl. Mater. Interfaces 2016, 8, 17728-17737.

(26) Gao, W.; Bie, M.; Liu, F.; Chang, P.; Quan, Y. Self-Healable and Reprocessable Polysulfide Sealants Prepared from Liquid Polysulfide Oligomer and Epoxy Resin. ACS Appl. Mater. Interfaces 2017, 9, 15798-15808.

(27) Canadell, J.; Goossens, H.; Klumperman, B. Self-Healing Materials Based on Disulfide Links. Macromolecules 2011, 44, 2536-2541.

(28) Zhang, B.; Digby, Z. A.; Flum, J. A.; Chakma, P.; Saul, J. M.; Sparks, J. L.; Konkolewicz, D. Dynamic Thiol-Michael Chemistry for Thermoresponsive Rehealable and Malleable Networks. Macromolecules 2016, 49, 6871-6878.

(29) Hohlbein, N.; Shaaban, A.; Bras, A. R.; Pyckhout-Hintzen, W.; Schmidt, A. M. Self-healing dynamic bond-based rubbers: understanding the mechanisms in ionomeric elastomer model systems. Phys. Chem. Chem. Phys. 2015, 17, 21005-21017.

(30) Cao, L.; Fan, J.; Huang, J.; Chen, Y. A robust and stretchable cross-linked rubber network with recyclable and self-healable capabilities based on dynamic covalent bonds. J. Mater. Chem. A 2019, 7, $4922-4933$. 